\title{
FOOT PRESSURE CHARACTERISTICS OF CHINESE OVERWEIGHT AND OBESE CHILDREN DURING GAIT
}

\section{CARACTERISTICILE PRESIUNII PLANTARE ÎN TIMPUL MERSULUI LA COPIII SUPRAPONDERALI ŞI OBEZI DIN CHINA}

\section{Shiyang YAN ${ }^{1}$, Linshan ZHANG ${ }^{2}$, Xiaoyun $\mathrm{LI}^{2}$, Ruoyi $\mathrm{LI}^{2}$, Nan $\mathrm{ZHOU}^{1}$, Xiaoyue CAI ${ }^{3}$, Luming YANG ${ }^{1 *}$}

${ }^{1}$ Key Laboratory of Leather Chemistry and Engineering (Sichuan University), Ministry of Education, Chengdu, China

${ }^{2}$ National Engineering Laboratory for Clean Technology of Leather Manufacture, Chengdu, China

${ }^{3}$ The First People's Hospital of Shuangliu County, Chengdu, China

\section{FOOT PRESSURE CHARACTERISTICS OF CHINESE OVERWEIGHT AND OBESE CHILDREN DURING GAIT}

ABSTRACT. There are differences in foot pressure characteristics depending on ethnicity. This is the first study to evaluate dynamic plantar pressures of overweight children, not only obese children in China, which can provide the pressure patterns of Mongoloid population with data references. Totally 438 children, including 228 boys and 209 girls, aged 7-16 years were recruited from China. Data of plantar pressures was collected by Footscan ${ }^{\circledR}$ plate system. All subjects were classified into groups of non-overweight, overweight and obesity based on body mass index (BMI). Overweight children displayed significantly higher peak pressures and impulses in the $4^{\text {th }}$ metatarsal, midfoot and heel relative to non-overweight children $(p<0.017)$. Elevated impulses and pressure-time integrals of obese children were found at the hallux when compared to non-overweight counterparts $(p=0.017)$. Pressure rates were higher in obese children on the metatarsals $(p<0.017)$. Excessive and repetitive overload for children can increase the risk of foot damage. Since significantly higher pressures at the hallux for obese children were found for the first time, we theorize that races and customs may affect the biomechanical function of the hallux or alter the walking habits of obese children rather than the skeletal structural changes responsible for this finding.

KEY WORDS: overweight; obesity; Chinese; children; dynamic plantar pressure

\section{CARACTERISTICILE PRESIUNII PLANTARE ÎN TIMPUL MERSULUI LA COPIII SUPRAPONDERALI ŞI OBEZI DIN CHINA}

REZUMAT. Caracteristicile presiunii plantare a piciorului diferă în funcţie de etnie. Acesta este primul studiu care evaluează presiunile plantare în dinamică la copiii supraponderali, nu doar la copiii obezi din China, cu posibilitatea de a oferi modele de presiune de referinţă ale populaţiei mongoloide. S-au recrutat în total 438 de copii din China, din care 228 băieţi şi 209 fete, cu vârsta cuprinsă între 7 şi 16 ani. Datele presiunilor plantare au fost colectate utilizând platforma de forţă Footscan ${ }^{\circledR}$. Subiecţii au fost clasificaţi în trei grupe: normali, supraponderali şi obezi, pe baza indicelui de masă corporală (IMC). Copiii supraponderali au prezentat presiuni maxime semnificativ mai mari şi impulsuri la nivelul celui de-al 4-lea metatarsian, în zona centrală a piciorului şi în zona călcâiului faţă de copiii cu greutate normală ( $<<0.017)$. S-au observat impulsuri şi integrale presiune-timp crescute la nivelul halucelui în cazul copiilor obezi în comparaţie cu copiii cu greutate normală ( $p=0.017$ ). Valorile de presiune au fost mai mari la nivelul metatarsienelor în cazul copiilor obezi ( $p<0.017)$. Supraîncărcarea excesivă şi repetitivă în cazul copiilor poate creşte riscul de leziuni la nivelul picioarelor. Întrucât s-au constatat pentru prima oară presiuni semnificativ mai mari la nivelul halucelui în cazul copiilor obezi, propunem teoria că rasele şi obiceiurile pot afecta mai degrabă funcţia biomecanică a halucelui sau modifica obiceiurile de mers ale copiilor obezi, decât modificările structurale ale scheletului responsabile de această constatare.

CUVINTE CHEIE: supraponderabilitate; obezitate; chinez; copii; presiune plantară dinamică

\section{LES CARACTÉRISTIQUES DE LA PRESSION PLANTAIRE CHEZ LES ENFANTS CHINOIS EN SURPOIDS ET OBÈSES PENDANT LA MARCHE}

RÉSUMÉ. Les caractéristiques de la pression plantaire varie selon l'origine ethnique. Cette étude est la première qui évalue les pressions plantaires dynamiques chez les enfants en surpoids, non seulement chez les enfants obèses de Chine avec la possibilité de fournir des modèles de référence de la pression de la population mongole. On a recruté un total de 438 enfants chinois, dont 228 garçons et 209 filles, âgés entre 7 et 16 ans. Les données de la pression plantaire ont été recueillies à l'aide de la plate-forme de force Footscan ${ }^{\circledR}$. Les sujets ont été classés en trois groupes : au poids normal, en surpoids ou obèses en fonction de l'indice de masse corporelle (IMC). Les enfants en surpoids avaient le niveau de pression maximale significativement plus élevé et des impulsions chez le 4-ème métatarsien, dans la zone centrale du pied et chez le talon, par rapport aux enfants ayant un poids normal $(p<0,017)$. Des impulsions et des intégrales pression-temps élevées ont été observées au gros orteil chez les enfants obèses par rapport aux enfants ayant un poids normal $(p=0,017)$. Les valeurs de pression sont plus élevées aux métatarses chez les enfants obèses $(p<0,017)$. La surcharge excessive et répétitive chez les enfants peut augmenter le risque de blessures aux jambes. On a constaté pour la première fois des pressions significativement plus élevées à l'orteil chez les enfants obèses, ensuite on propose la théorie selon laquelle les races et les habitudes peuvent affecter plutôt la fonction biomécaniques de l'orteil ou changer les habitudes de la marche des enfants obèses que les changements structurels squelettiques responsables de la cette constatation.

MOTS-CLÉS: surpoids, obésité, chinois, enfants, pression plantaire dynamique

\footnotetext{
* Correspondence to: Luming YANG, Key Laboratory of Leather Chemistry and Engineering (Sichuan University), Ministry of Education, Sichuan University, No.24 in South pare of First ring road, Wuhou district, Chengdu, Sichuan, China, email: yangluminglulu@qq.com
} 


\section{INTRODUCTION}

Obesity is known as one of the three recognized global health hazards along with smoking and AIDS. The total number of children in the world has grown to 1.6 billion [1]. As reported, seventy per cent of obesity in childhood has the possibility of becoming adult obesity [2]. Since 2009, the percentage of obese children is approximately $10 \%$ in China, and with the growth of $8 \%$ per year [3]. Several studies found that obesity has a detrimental impact on the bone strength of children as a result of weaker bone strength in obese children [4-6]. In this regard, overload in children can adversely affect the function and structure of lower limbs, especially of foot.

Feet as the base of human body supporting the kinematics and kinetics of lower limbs cannot be ignored. In an attempt to quantify and characterize the functional capacity of foot during locomotion, studies on gait characteristics [7], plantar pressure distributions [8], foot structure [9] and electromyography [10] have been conducted with obese children. Plantar pressure distributions can intuitively reflect the total loading as well as the loading in each region of the foot.

Plantar pressure is affected by age, body mass, walking speed and daily activities [11]. There are studies showing that different races and customs may lead to the diversity of plantar pressure. [12-13]. Cavanagh et al. [14] pointed out that the correlation coefficient of plantar max force of Caucasian and body mass is 0.37 , higher than that of Mongoloid population. All the literature mentioned above fully proved that foot pressure characteristics of different races were unique. In view of this, we just explored the plantar pressure of Chinese overweight and obese children which can provide the plantar pressure distributions of Mongoloid population with data references.

Yan et al. [8] has reported that obese children displayed weaker walking stability with flatter foot pattern, and larger dynamic plantar pressure changes. Excessive and repetitive loads can lead to a high risk of developing foot injuries and pathologies [15]. Butterworth et al. [16] demonstrated that body mass and fat mass were

\section{INTRODUCERE}

Obezitatea este cunoscută ca unul dintre cele trei riscuri pentru sănătate la nivel mondial, împreună cu fumatul și SIDA. Numărul total de copii la nivel global a crescut la 1,6 miliarde [1]. S-a raportat că în șaptezeci la sută din cazuri, obezitatea din copilărie se poate menține și la maturitate [2]. Începând cu anul 2009, procentul de copii obezi este de aproximativ 10\% în China, cu o creștere de $8 \%$ pe an [3]. Mai multe studii au constatat că obezitatea are un impact negativ asupra rezistenței oaselor copiilor ca urmare a rezistenței osoase mai slabe la copiii obezi [4-6]. Astfel, suprasarcina în cazul copiilor poate afecta negativ funcționarea și structura membrelor inferioare, în special la nivelul labei piciorului.

Ca bază a corpului uman, labele picioarelor susțin cinematic și cinetic membrele inferioare și nu pot fi ignorate. Într-o încercare de a cuantifica și caracteriza capacitatea funcțională a piciorului în timpul locomoției, s-au efectuat studii cu privire la caracteristicile de mers [7], distribuția presiunilor plantare [8], structura piciorului [9] și testele de electromiografie [10] în cazul copiilor obezi. Distribuția presiunilor plantare poate reflecta în mod intuitiv încărcarea totală, precum și încărcarea în fiecare regiune a piciorului.

Presiunea plantară este influențată de vârstă, masa corporală, viteza de mers și activitățile de zi cu zi [11]. Există studii care arată că diferite rase și obiceiuri pot duce la diferențe privind presiunile plantare. [12-13]. Cavanagh și colab. [14] au subliniat faptul că coeficientul de corelație al forței plantare maxime la populația caucaziană și masa corporală este de 0,37, mai mare decât cea a populației mongoloide. Literatura de specialitate menționată mai sus a dovedit clar unicitatea caracteristicilor de presiune a piciorului la diferite rase. Având în vedere acest lucru, am explorat presiunea plantară doar la copiii supraponderali și obezi din China, pentru a obține distribuțiile de presiune plantară de referință la populația mongoloidă.

Yan și colab. [8] au raportat o stabilitate mai slabă în mers la copiii obezi, cu picior mai plat și modificări mai mari ale presiunii plantare în dinamică. Încărcarea excesivă și repetitivă poate duce la un risc crescut de a dezvolta leziuni ale picioarelor și patologii [15]. Butterworth și colab. [16] au demonstrat că masa corporală și procentul de grăsime s-au numărat printre 
among the factors causing foot pain. Several studies have found that overweight and obese children experienced higher plantar pressures in foot regions $[9,15,17]$. Small variations in foot pressure characteristics must be incorporated to the shoe design to satisfy the shoe functionality and comfort requirements of overweight and obese children.

However, most studies of plantar pressure distribution, gait characteristics and foot structure highlighted the comparison between normal children and obese children [7-9, 17-19], few studies have compared in pairs among nonoverweight, overweight and obese children. The aim of this study was to compare the dynamic plantar pressure between any two means of Chinese non-overweight, overweight and obese children for the first time. As reported, overweight children would be involved into an increased risk of ankle injury [20]. Furthermore, overweight children are accepted as a potentially high-risk group of developing obesity and are worthy of attention, viewing to find more specific information about plantar pressure distributions of Chinese children associated with magnitude of excessive mass.

\section{RESEARCH METHODS AND PROCEDURES}

\section{Subjects}

Totally 438 children, including 228 boys and 209 girls, aged between 7-16 years were initially recruited from several consenting primary schools and middle schools throughout Yantai City, China. Excluding foot diseases, musculoskeletal deformity and other health problems, the valid samples were 393 (age: 10.5 \pm 2.2 years; height: $148.2 \pm 14.4 \mathrm{~cm}$; body mass: $49.1 \pm 18.0 \mathrm{~kg}$; BMI: $\left.21.7 \pm 4.8 \mathrm{~kg} / \mathrm{m}^{2}\right)$. According to the body mass index (BMI) reference norm established by Group of China Obesity Task Force [21], which was used to screen overweight and obesity based on age and sex in Chinese children and adolescents, all participants were classified into three groups: non-overweight, overweight and obese, descriptive data was shown in Table 1. All research procedures and methods were approved by Sichuan University (China) Human Research Ethics Committee. Written informed factorii care cauzează dureri la nivelul piciorului. Mai multe studii au constatat presiuni plantare mai mari în regiunile piciorului în cazul copiilor supraponderali și obezi $[9,15,17]$. Micile variații ale caracteristicilor de presiune ale piciorului trebuie să fie încorporate la proiectarea încălțămintei pentru a satisface cerințele de funcționalitate și de confort ale pantofilor pentru copiii supraponderali și obezi.

$\mathrm{Cu}$ toate acestea, cele mai multe studii au efectuat comparații între copiii cu greutate normală și cei obezi privind distribuția presiunii plantare, caracteristicile mersului și structura piciorului [7-9, 17-19]; puține studii au comparat în perechi copiii cu greutate normală, cei supraponderali, și cei obezi. Scopul acestui studiu a fost acela de a compara pentru prima oară presiunea plantară în dinamică între oricare două grupe de copii chinezi cu greutate normală, supraponderali și obezi. După cum reiese din studiu, copiii supraponderali prezintă un risc crescut de leziuni la nivelul gleznei [20]. Mai mult, copiii supraponderali sunt considerați un grup cu risc potențial ridicat de a dezvolta obezitate, fiind de interes în vederea adunării mai multor informații specifice despre distribuția presiunii plantare la copiii chinezi cu greutate excesivă.

\section{METODE ȘI PROCEDURI DE CERCETARE}

\section{Subiecți}

S-au recrutat în total 438 de copii, dintre care 228 băieți și 209 fete, cu vârste cuprinse între 7 și 16 ani, din mai multe școli primare și gimnaziale din orașul Yantai, China, cu consimțământul acestora. După excluderea bolilor de picioare, deformărilor musculoscheletice și a altor probleme de sănătate, au rămas 393 de subiecți valabili (vârsta: 10,5 \pm 2,2 ani; înălțime: $148,2 \pm 14,4 \mathrm{~cm}$; masa corporală: 49,1 $\pm 18,0 \mathrm{~kg}$; IMC: $\left.21,7 \pm 4,8 \mathrm{~kg} / \mathrm{m}^{2}\right)$. Conform indicelui de masă corporală (IMC) de referință stabilit de Grupul pentru Combaterea Obezității din China [21], care a fost utilizat pentru a selecta copiii și adolescenții chinezi supraponderali și obezi în funcție de vârstă și sex, toți participanții au fost clasificați în trei grupe: cu greutate normală, supraponderali și obezi, iar datele descriptive sunt prezentate în Tabelul 1. Toate metodele și procedurile de cercetare 
consent was obtained from all participants prior to data collection under supervision. au fost aprobate de către Comitetul de Etică în Cercetare al Universității Sichuan (China). Toți participanții și-au dat consimțământul în scris înainte de colectarea datelor sub supraveghere.

Table 1: Baseline data* of subjects

Tabelul 1: Datele de bază* ale subiecţilor

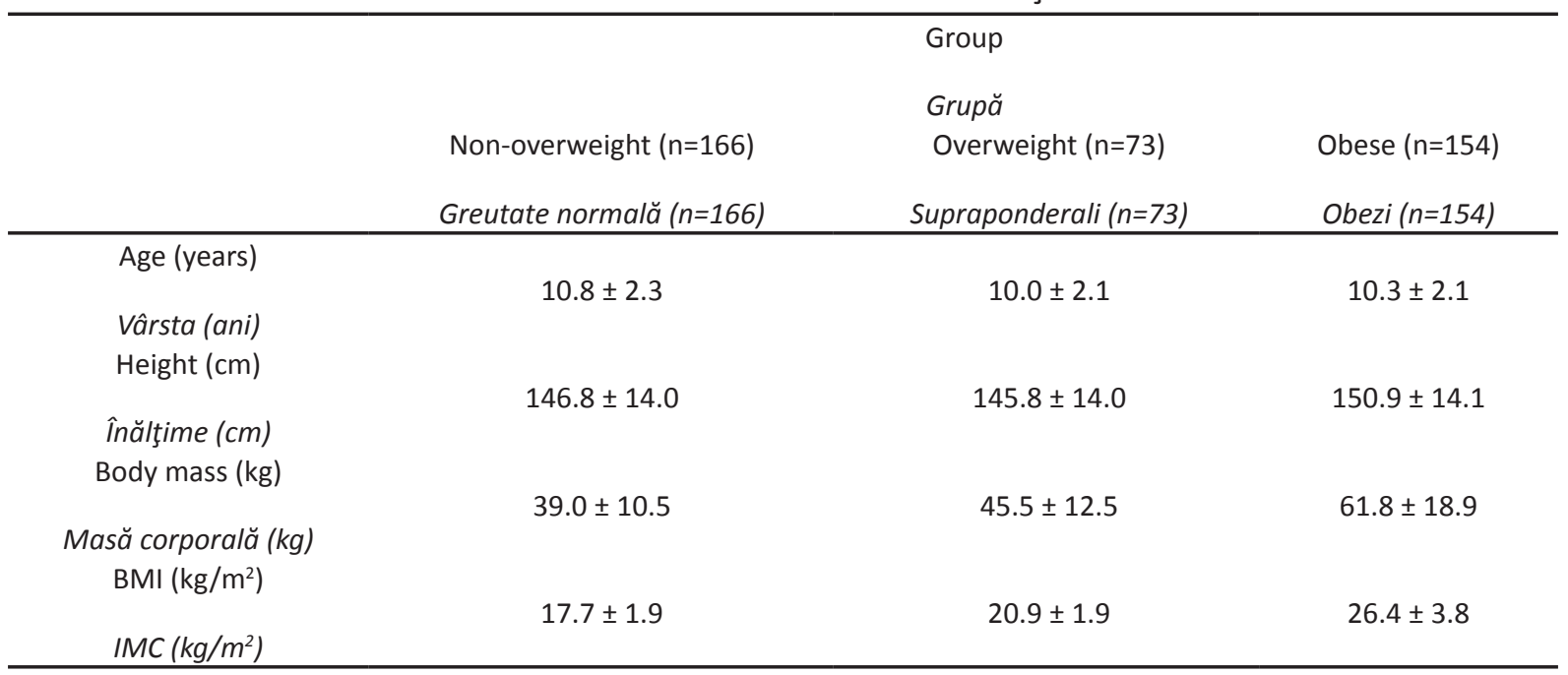

*Values are the mean \pm SD.

*Valorile reprezintă mediile $\pm S D$.

\section{Experimental Methods}

Each participant's height was measured once to the nearest $0.1 \mathrm{~cm}$ using a calibrated height and weight scale with barefoot, while body mass was measured once to the nearest $0.5 \mathrm{~kg}$ using the same instrument. BMI was then calculated using body mass divided by height squared $\left(\mathrm{kg} / \mathrm{m}^{2}\right)$. To minimize the artificial error, all the anthropometric measurements were measured by a fixed experimenter.

A Footscan ${ }^{\circledast}$ plantar pressure plate system (RSscan International, Olen, Belgium) was used to test the plantar pressure during gait. This plate system included a $40 \mathrm{~cm} \times 100 \mathrm{~cm}$ platform with 4 sensors per square centimeter, and a high sample frequency of $253 \mathrm{~Hz}$ which can capture more precise data from dynamic plantar pressures. This plate was mounted on a smooth and level ground. Each participant was tested using a two-step gait initiation protocol [22], that is to say, after some practice under the experimenter's guidance, participants were then required to walk barefoot three times or more, crossing the plate at self-preferred speed to complete the test procedure. Participants stood about a meter away in front of the edge

\section{Metode experimentale}

S-a măsurat înălțimea fiecărui participant o singură dată cu o marjă de $0,1 \mathrm{~cm}$, folosind o scară de înălțime și greutate gradată, subiecții nepurtând încălțăminte, iar masa corporală a fost măsurată o singură dată cu o marjă de $0,5 \mathrm{~kg}$, folosind același instrument. IMC a fost calculat împărțind masa corporală la pătratul înălțimii $\left(\mathrm{kg} / \mathrm{m}^{2}\right)$. Pentru a reduce la minimum eroarea artificială, toate măsurătorile antropometrice au fost măsurate de aceeași persoană.

S-a utilizat platforma Footscan ${ }^{\circledR}$ (RSscan International, Olen, Belgia) pentru a măsura presiunea plantară în timpul mersului. Acest sistem cuprinde o platformă de $40 \mathrm{~cm} \times 100 \mathrm{~cm}$, cu 4 senzori pe centimetru pătrat, și o frecvență mare de eșantionare de $253 \mathrm{~Hz}$, care poate capta date mai exacte privind presiunile plantare în dinamică. Această platformă a fost montată pe un teren neted și uniform. Pentru fiecare participant, testul a constat într-un protocol de inițiere a mersului în două etape [22], adică, după o serie de exerciții, sub îndrumarea experților, participanților li s-a cerut să traverseze platforma desculți de trei ori sau mai mult, cu o viteză la alegere pentru finalizarea procedurii de testare. 
of platform, and then cross the walkway to the ground. Three trials of a subject were selected as valid by the following criteria: a whole gait cycle on the plate during natural walking but not aiming at.

\section{Data Analysis}

Hylton [23] has suggested that by only selecting one foot or by averaging observations from both feet, spurious findings from paired data can be avoided, the author hereby chose the right foot (the dominant foot) to analyze the statistical differences. Hennig et al. [24] and Yan et al. [25] has reported that no difference was found in plantar pressures between girls and boys. Mean values of three valid trials of each right foot were calculated and analyzed. Ten plantar anatomical regions were defined by Footscan 7 Gait $2^{\text {nd }}$ generation (V7. 97) (Figure 1) which is an application program software of Footscan ${ }^{\circledR}$ plate system. Data of plantar pressures was collected by the instrument. Biomechanical parameters of peak pressure, maximum force, impulse, pressure-time integral and pressure rate were extracted from database for statistical analysis.
Participanții au traversat platforma pornind de la aproximativ un metru distanță de marginea platformei. S-au selectat ca fiind valabile trei încercări ale unui subiect pe baza următoarelor criterii: efectuarea unui ciclu întreg de mers pe platformă, adoptând un mers natural.

\section{Analiza datelor}

Hylton [23] a sugerat că, prin selectarea unui singur picior sau prin calcularea mediei observațiilor de la ambele picioare, se pot evita constatări false din datele asociate; astfel, autorul a ales în acest studiu piciorul drept (piciorul dominant) pentru a analiza diferențele statistice. Hennig și colab. [24] și Yan și colab. [25] au raportat că nu s-a constatat nicio diferență privind presiunile plantare între fete și băieți. S-au calculat și analizat valorile medii a trei încercări valabile pentru piciorul drept. Programul Footscan 7 generația a 2-a (V7. 97), aferent sistemului de măsurare a presiunii Footscan ${ }^{\circledR}$, a definit zece regiuni anatomice de analiză (Figura 1). Datele privind presiunile plantare au fost colectate cu ajutorul acestui instrument. Din baza de date s-au extras parametri biomecanici cum ar fi presiunea maximă, forța maximă, impulsul, integrala presiune-timp și presiunea, pentru analiza statistică.

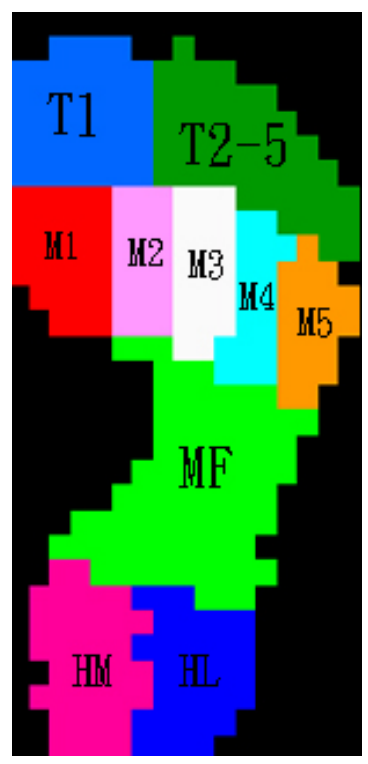

Figure 1. Ten anatomical regions of foot. T1: hallux, T2-5: $2^{\text {nd }}-5^{\text {th }}$ toes, $M 1: 1^{\text {st }}$ metatarsal, $M 2: 2^{\text {nd }}$ metatarsal, M3: $3^{\text {rd }}$ metatarsal, M4: $4^{\text {th }}$ metatarsal, M5: $5^{\text {th }}$ metatarsal, MF: midfoot, HM: heel medial, $\mathrm{HL}$ : heel lateral

Figura 1. Cele zece regiuni anatomice ale piciorului. T1: haluce, T2-5: degetele 2-5, M1: primul metatarsian, M2: al 2-lea metatarsian, M3: al 3-lea metatarsian, M4: al 4-lea metatarsian, M5: al 5-lea metatarsian, MF: zona centrală a piciorului, HM: zona interioară a călcâiului, $\mathrm{HL}$ : zona exterioară a călcâiului 
Based on the extracted data above, SPSS software (version 17.0 for Windows; SPSS Corp., Chicago, IL) was used to analyze the intergroup and intragroup differences. Onesample Kolmogorov-Smirnov-test (K-S) was used to perform the normality test of all data, and analysis result shows that not all data conforms to normal distribution in all regions for each group. Kruskal-Walls $\mathrm{H}$-test and Chi-square test were then selected to compare peak pressure, maximum force, impulse, pressure-time integral and pressure rate in all anatomical regions among three groups classified above to certify whether there were any significant differences. $p$ values less than 0.05 were perceived as significant in all groups. Since repeated hypothesis testing makes calibration standard $\alpha$ error expansion, when performing Post Hoc Multiple comparisons, calibration standard $\alpha$ was calibrated by the following formula: $\alpha^{\prime}=\alpha / N$ ( $N$ represents amount of testing). Bivariate Correlation was conducted to analyze the potential associations of age, body mass and BMI with peak pressures and pressuretime integrals. The magnitude of correlation coefficient $(r)$ is divided into four grades: low (0$0.25)$; weak (0.26-0.50); moderate (0.51-0.75); very strong (0.76-1.00) [26].

\section{RESULTS}

Descriptive data of the maximum forces and peak pressures in non-overweight, overweight and obese children are summarized in Table 2. Significantly higher maximum forces and peak pressures were found in the $4^{\text {th }}$ metatarsal, midfoot, medial heel and lateral heel between non-overweight $(p=0.004, p=0.004, p$ $=0.011)$ and overweight children $(p=0.009, p=$ $0.003, p=0.003, p=0.012$ ). When obese children were compared to those both overweight and non-overweight children, significant differences were found in all regions excepting for the hallux and $2^{\text {nd }}-5^{\text {th }}$ toes $(p<0.017)$. However, significantly higher maximum forces $(p=0.004)$ and peak pressures $(p=0.015)$ under the hallux in those who were obese when compared to non-overweight children.

Statistical characteristics of impulses and pressure-time integrals are summarized in Table
Pe baza datelor extrase de mai sus, s-a utilizat programul SPSS (versiunea 17.0 pentru Windows, SPSS Corp., Chicago, IL) pentru a analiza diferențele dintre grupe și în interiorul grupelor. S-a utilizat testul Kolmogorov-Smirnov (K-S) pentru un singur eșantion pentru a determina normalitatea datelor, iar rezultatul analizei a arătat că nu toate datele sunt conforme cu distribuția normală în toate regiunile la fiecare grupă. S-au selectat apoi testele Kruskal-Walls $\mathrm{H}$ și Chi-pătrat pentru a compara presiunea maximă, forța maximă, impulsul, integrala presiune-timp și presiunea în toate regiunile anatomice între cele trei grupe menționate mai sus pentru a confirma dacă au existat diferențe semnificative. Valorile $p$ mai mici decât 0,05 au fost percepute ca fiind semnificative în toate grupele. Întrucât testarea repetată a ipotezelor duce la erori de calibrare standard $\alpha$, la efectuarea unor comparații multiple post hoc, calibrarea standard $\alpha$ a fost efectuată cu următoarea formulă: $\alpha^{\prime}=$ $\alpha / N$ (N reprezintă numărul de testări). S-a realizat corelarea bivariată pentru a analiza potențialele asocieri ale vârstei, masei corporală și IMC cu presiunile maxime și integralele presiune-timp. Mărimea coeficientului de corelație $(r)$ este împărțită în patru niveluri: scăzută $(0-0,25)$; slabă $(0,26-0,50)$; moderată $(0,51-0,75)$; foarte puternică $(0,76-1,00)[26]$.

\section{REZULTATE}

Datele descriptive ale forțelor maxime și ale presiunilor maxime măsurate la copiii cu greutate normală, supraponderali și obezi sunt prezentate pe scurt în Tabelul 2. S-au constatat forțe maxime și presiuni maxime semnificativ mai mari la nivelul celui de-al 4-lea metatarsian, în zona centrală a piciorului, în zonele interioară și exterioară ale călcâiului la copiii cu greutate normală ( $p=0,004, p=0,004, p=0,011)$ și la copiii supraponderali $(p=0,009, p=0,003, p=$ $0,003, p=0,012)$. Comparând datele obținute în cazul copiilor obezi cu cele ale copiilor supraponderali și ale celor cu greutate normală, s-au constatat diferențe semnificative în toate regiunile cu excepția halucelui și a degetelor 2-5 ( $p<0,017)$. Cu toate acestea, s-au observat forțe maxime $(p=0,004)$ și presiuni maxime $(p=$ $0,015)$ semnificativ mai mari în zona halucelui la copiii obezi în comparație cu copiii cu greutate normală. 
Table 2: Descriptive statistics* of maximum force $(\mathrm{N})$ and peak pressure $\left(\mathrm{N} / \mathrm{cm}^{2}\right)$ for non-overweight $(n=166)$, overweight $(n=73)$ and obese $(n=154)$ children

Tabelul 2: Statistici descriptive* ale forţei maxime (N) şi presiunea maximă $\left(\mathrm{N} / \mathrm{cm}^{2}\right)$ la copiii cu greutate normală $(n=166)$, supraponderali $(n=73)$ şi obezi $(n=154)$

\begin{tabular}{|c|c|c|c|c|c|c|}
\hline \multirow{3}{*}{$\begin{array}{l}\text { Region } \\
\text { Regiune }\end{array}$} & \multicolumn{3}{|c|}{$\begin{array}{l}\text { Maximum force }(\mathrm{N}) \\
\text { Forţa maximă }(\mathrm{N})\end{array}$} & \multicolumn{3}{|c|}{ Peak pressure $\left(\mathrm{N} / \mathrm{cm}^{2}\right)$} \\
\hline & Group 1 & Group 2 & Group 3 & Group 1 & Group 2 & Group 3 \\
\hline & Grupa 1 & Grupa 2 & Grupa 3 & Grupa 1 & Grupa 2 & Grupa 3 \\
\hline $\mathrm{T} 1$ & $69.58(29.88)$ & $75.45(34.54)$ & $84.15(41.15)^{c}$ & $4.68(1.68)$ & $5.01(2.04)$ & $5.33(2.14)^{c}$ \\
\hline T2-5 & $25.19(13.75)$ & $21.92(11.43)$ & $26.23(15.89)$ & $1.26(0.57)$ & $1.17(0.54)$ & $1.21(0.65)$ \\
\hline M1 & 77.15 (42.83) & $81.38(39.58)^{b}$ & $101.08(55.01)^{c}$ & $4.93(2.28)$ & $4.95(1.86)^{b}$ & $5.63(2.50)^{c}$ \\
\hline M2 & $94.87(44.65)$ & $97.55(53.39)^{b}$ & $130.22(59.13)^{c}$ & $10.68(3.94)$ & $10.25(4.37)^{b}$ & $12.3(4.24)^{c}$ \\
\hline M3 & $88.44(36.12)$ & $96.67(42.93)^{b}$ & $135.9(58.29)^{c}$ & $10.58(3.29)$ & $10.94(3.63)^{b}$ & $13.76(4.28)^{c}$ \\
\hline M4 & $60.15(26.08)^{\mathrm{a}}$ & $72.82(34.31)^{b}$ & $103.35(45.60)^{c}$ & $7.38(2.75)^{\mathrm{a}}$ & $8.52(3.23)^{b}$ & $10.84(3.75)^{c}$ \\
\hline M5 & $31.34(18.25)$ & $37.83(22.73)^{b}$ & $59.34(30.66)^{c}$ & $3.44(1.76)$ & $3.98(2.02)^{b}$ & $5.55(2.39)^{c}$ \\
\hline $\mathrm{MF}$ & $76.89(41.44)^{\mathrm{a}}$ & $100.80(59.76)^{b}$ & $164.68(81.04)^{c}$ & $2.24(0.94)^{a}$ & $2.74(1.24)^{b}$ & $3.88(1.41)^{\mathrm{c}}$ \\
\hline HM & $140.61(51.67)^{\mathrm{a}}$ & $161.47(60.47)^{\mathrm{b}}$ & $206.29(84.97)^{c}$ & $8.52(2.22)^{\mathrm{a}}$ & $9.37(2.27)^{b}$ & $10.60(2.94)^{c}$ \\
\hline $\mathrm{HL}$ & 112.14 (38.9) & $127.05(48.17)^{\mathrm{b}}$ & $160.34(62.94)^{c}$ & $7.79(1.94)^{\mathrm{a}}$ & $8.56(2.18)^{b}$ & $9.61(2.42)^{c}$ \\
\hline
\end{tabular}

*Values are the mean (SD) of three trials.

Group 1: non-overweight; group 2: overweight; group 3: obese.

${ }^{a}$ Significant difference $\left(p<\alpha^{\prime}=0.017\right)$ between group 1 and group 2; bignificant difference $(p<0.017)$ between group 2 and group 3; 'Significant difference $(p<0.017)$ between group 3 and group 1.

* Valorile reprezintă mediile (SD) a trei încercări.

Grupa 1: greutate normală; grupa 2: supraponderali; grupa 3: obezi.

${ }^{a}$ Diferenţă semnificativă $\left(p<\alpha^{\prime}=0,017\right)$ între grupa 1 şi grupa $2 ;{ }^{b}$ Diferenţă semnificativă $(p<0,017)$ între grupa 2 şi grupa 3; 'Diferenţă semnificativă $(p<0,017)$ între grupa 3 şi grupa 1.

3. Significantly increased foot impulses $(p=$ $0.001, p=0, p=0.001, p=0.001$ ) and pressuretime integrals $(p=0.006, p=0, p=0.001, p=$ 0.001 ) were observed in the $4^{\text {th }}$ metatarsal, midfoot, medial heel and lateral heel between non-overweight and overweight children. Elevated impulses $(p=0)$ and pressure-time $(p=$ 0 ) integrals of obese children were found at the
Caracteristicile statistice ale impulsurilor și integralelor presiune-timp sunt prezentate pe scurt în Tabelul 3. S-au observat impulsuri ale piciorului $(p=0,001, p=0, p=0,001, p=0,001)$ și integrale presiune-timp $(p=0,006, p=0, p=$ $0,001, p=0,001$ ) semnificativ mai mari la nivelul celui de-al 4-lea metatarsian, în zona centrală a piciorului, în zonele interioară și exterioară ale 
Table 3: Descriptive statistics* of impulse $(\mathrm{N} \cdot \mathrm{s})$ and pressure-time integral $\left(\mathrm{N} / \mathrm{cm}^{2} \cdot \mathrm{s}\right)$ for nonoverweight $(n=166)$, overweight $(n=73)$ and obese $(n=154)$ children

Tabelul 3: Statistici descriptive* ale impulsului (N.s) şi integralei presiune-timp $\left(\mathrm{N} / \mathrm{cm}^{2} \cdot \mathrm{s}\right)$ la copiii cu greutate normală $(n=166)$, supraponderali $(n=73)$ şi obezi $(n=154)$

\begin{tabular}{|c|c|c|c|c|c|c|}
\hline \multirow{3}{*}{$\begin{array}{l}\text { Region } \\
\text { Regiune }\end{array}$} & \multirow{3}{*}{ Group 1} & \multirow{3}{*}{ 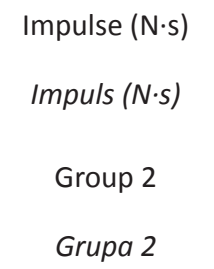 } & \multirow{3}{*}{$\begin{array}{l}\text { Group } 3 \\
\text { Grupa } 3\end{array}$} & \multicolumn{3}{|c|}{$\begin{array}{l}\text { Pressure-time integral }\left(\mathrm{N} / \mathrm{cm}^{2} \cdot \mathrm{s}\right) \\
\text { Integrala presiune-timp }\left(\mathrm{N} / \mathrm{cm}^{2} \cdot \mathrm{s}\right)\end{array}$} \\
\hline & & & & Group 1 & Group 2 & Group 3 \\
\hline & & & & Grupa 1 & Grupa 2 & Grupa 3 \\
\hline $\mathrm{T} 1$ & $18.11(9.62)$ & $21.15(12.31)$ & $24.71(14.84)^{c}$ & $1.21(0.59)$ & $1.40(0.75)$ & $1.56(0.81)^{c}$ \\
\hline T2-5 & $5.80(3.67)$ & $5.42(3.36)$ & $6.64(4.85)$ & $0.29(0.16)$ & $0.28(0.16)$ & $0.30(0.20)$ \\
\hline M1 & $23.18(13.36)$ & $25.76(13.54)^{b}$ & $34.78(21.85)^{c}$ & $1.48(0.71)$ & $1.58(0.66)$ & $1.93(1.02)^{c}$ \\
\hline M2 & $30.84(16.96)$ & $31.88(18.64)^{b}$ & $46.11(23.75)^{c}$ & $3.45(1.50)$ & $3.38(1.56)^{b}$ & $4.34(1.72)^{\mathrm{c}}$ \\
\hline M3 & $29.71(14.70)$ & $32.70(15.82)^{b}$ & $49.15(23.66)^{c}$ & $3.54(1.38)$ & $3.70(1.44)^{b}$ & $4.95(1.77)^{\mathrm{c}}$ \\
\hline M4 & $20.68(10.31)^{\mathrm{a}}$ & $26.38(14.20)^{\mathrm{b}}$ & $38.75(18.95)^{c}$ & $2.54(1.09)^{\mathrm{a}}$ & $3.04(1.35)^{b}$ & $4.04(1.55)^{c}$ \\
\hline M5 & $9.24(6.09)$ & $12.00(8.25)^{b}$ & $19.99(11.60)^{c}$ & $1.01(0.60)$ & $1.24(0.75)^{\mathrm{b}}$ & $1.86(0.91)^{\mathrm{c}}$ \\
\hline MF & $22.14(14.06)^{\mathrm{a}}$ & $33.28(23.79)^{\mathrm{b}}$ & $57.25(36.94)^{c}$ & $0.64(0.33)^{\mathrm{a}}$ & $0.90(0.52)^{b}$ & $1.32(0.67)^{c}$ \\
\hline $\mathrm{HM}$ & $38.26(17.72)^{a}$ & $48.47(23.11)^{b}$ & $63.24(32.81)^{c}$ & $2.32(0.86)^{a}$ & $2.82(1.12)^{b}$ & $3.24(1.26)^{\mathrm{c}}$ \\
\hline $\mathrm{HL}$ & $29.89(13.13)^{a}$ & $37.42(17.77)^{b}$ & $48.59(24.08)^{c}$ & $2.09(0.76)^{\mathrm{a}}$ & $2.51(0.95)^{b}$ & $2.90(1.06)^{c}$ \\
\hline
\end{tabular}

*Values are the mean (SD) of three trials.

Group 1: non-overweight; group 2: overweight; group 3: obese.

${ }^{a}$ Significant difference $\left(p<\alpha^{\prime}=0.017\right)$ between group 1 and group 2; ${ }^{b}$ Significant difference $(p<0.017)$ between group 2 and group 3; 'Significant difference $(p<0.017)$ between group 3 and group 1.

*Valorile reprezintă mediile (SD) a trei încercări.

Grupa 1: greutate normală; grupa 2: supraponderali; grupa 3: obezi.

${ }^{a}$ Diferenţă semnificativă $\left(p<\alpha^{\prime}=0,017\right)$ între grupa 1 şi grupa $2 ;{ }^{b}$ Diferenţă semnificativă $(p<0,017)$ între grupa 2 şi grupa 3;

${ }^{c}$ Diferenţă semnificativă $(p<0,017)$ între grupa 3 şi grupa 1.

hallux that merit attention when compared to their non-overweight counterparts.

Pressure rates were larger in obese children when compared to non-overweight and overweight children (Table 4). In addition, statistical analyses indicated that significant differences mainly focused on the metatarsals $(p<0.017)$. No significant difference existed between the children who were non-overweight and overweight. călcâiului la copiii cu greutate normală și la cei supraponderali. S-au constatat impulsuri $(p=0)$ și integrale presiune-timp $(p=0)$ crescute în zona halucelui la copiii obezi, fapt care merită atenție în comparație cu grupa de copii cu greutate normală.

Presiunea a fost mai mare la copiii obezi, în comparație cu cei cu greutate normală și cei obezi (Tabelul 4). În plus, analizele statistice au indicat că există diferențe semnificative în principal la nivelul metatarsienelor $(p<0,017)$. 
Table 4: Descriptive statistics* of pressure rate $\left(\mathrm{N} / \mathrm{cm}^{2} \cdot \mathrm{ms}\right)$ for non-overweight $(\mathrm{n}=166)$, overweight $(n=73)$ and obese $(n=154)$ children

Tabelul 4: Statistici descriptive* ale presiunii $\left(\mathrm{N} / \mathrm{cm}^{2} \cdot \mathrm{ms}\right)$ la copiii cu greutate normală $(\mathrm{n}=166)$, supraponderali $(n=73)$ şi obezi $(n=154)$

\begin{tabular}{|c|c|c|c|}
\hline \multirow{3}{*}{$\begin{array}{l}\text { Region } \\
\text { Regiune }\end{array}$} & \multicolumn{3}{|c|}{ Pressure rate $\left(\mathrm{N} / \mathrm{cm}^{2} \cdot \mathrm{ms}\right)$} \\
\hline & \multicolumn{3}{|c|}{ Presiunea $\left(\mathrm{N} / \mathrm{cm}^{2} \cdot \mathrm{ms}\right)$} \\
\hline & Group 1 & Group 2 & Group 3 \\
\hline & Grupa 1 & Grupa 2 & Grupa 3 \\
\hline T1 & $0.02(0.01)$ & $0.02(0.01)$ & $0.02(0.01)$ \\
\hline T2-5 & $0.01(0.01)$ & $0.01(0.02)$ & $0.01(0.01)$ \\
\hline M1 & $0.02(0.01)$ & $0.02(0.01)$ & $0.02(0.01)^{c}$ \\
\hline M2 & $0.03(0.02)$ & $0.03(0.02)^{b}$ & $0.03(0.02)$ \\
\hline M3 & $0.03(0.02)$ & $0.03(0.01)^{b}$ & $0.04(0.02)^{c}$ \\
\hline M4 & $0.03(0.02)$ & $0.03(0.01)^{b}$ & $0.03(0.02)^{c}$ \\
\hline M5 & $0.02(0.02)$ & $0.02(0.01)^{b}$ & $0.02(0.02)^{c}$ \\
\hline MF & $0.02(0.02)$ & $0.02(0.02)^{b}$ & $0.03(0.02)^{c}$ \\
\hline HM & $0.25(0.24)$ & $0.22(0.19)$ & $0.23(0.16)$ \\
\hline $\mathrm{HL}$ & $0.29(0.33)$ & $0.25(0.26)$ & $0.30(0.26)$ \\
\hline
\end{tabular}

*Values are the mean (SD) of three trials.

Group 1: non-overweight; group 2: overweight; group 3: obese.

${ }^{a}$ Significant difference $\left(p<\alpha^{\prime}=0.017\right)$ between group 1 and group 2; ${ }^{b}$ Significant difference $(p<0.017)$ between group 2 and group 3; 'Significant difference $(p<0.017)$ between group 3 and group 1.

*Valorile reprezintă mediile (SD) a trei încercări.

Grupa 1: greutate normală; grupa 2: supraponderali; grupa 3: obezi.

${ }^{a}$ Diferenţă semnificativă $\left(p<\alpha^{\prime}=0,017\right)$ între grupa 1 şi grupa $2 ;{ }^{b}$ Diferenţă semnificativă $(p<0,017)$ între grupa 2 şi grupa 3; ${ }^{c}$ Diferenţă semnificativă $(p<0,017)$ între grupa 3 şi grupa 1.

Maximum force and peak pressure during gait correlated to age, body mass and $\mathrm{BMI}$ are shown in Table 5. Both maximum force and peak pressure displayed significantly low positive correlations to age, body mass and BMI.

\section{DISCUSSIONS}

This study assessed plantar pressure distributions of non-overweight, overweight and obese children aged 7 to 16 in China during gait. The plantar pressure characteristics for maximum forces and peak pressures are evidently higher in obese children, followed by overweight individuals, in all defined plantar regions, excluding the $2^{\text {nd }}-5^{\text {th }}$ metatarsals that,
Nu a existat nicio diferență semnificativă între copiii cu greutate normală și cei supraponderali.

Forța maximă și presiunea maximă în timpul mersului corelate cu vârsta, masa corporală și IMC sunt prezentate în Tabelul 5 . Atât forța maximă, cât și presiunea maximă prezintă corelații pozitive semnificativ mai mici pentru vârstă, masă corporală și IMC.

\section{DISCUȚII}

Acest studiu a evaluat distribuția presiunii plantare în timpul mersului la copiii cu greutate normală, supraponderali și obezi din China, cu vârstele între 7 și 16 ani. Caracteristicile presiunii plantare pentru forțele maxime și 
Table 5: Pearson correlation analysis between age, body mass and BMI and peak pressure, pressure-time integral

Tabelul 5: Analiza de corelaţie Pearson între vârstă, masă corporală şi IMC şi presiunea maximă şi integrala presiune-timp

\begin{tabular}{cccc}
\hline $\begin{array}{c}\text { Items } \\
\text { Parametri }\end{array}$ & $\begin{array}{c}\text { Age } \\
\text { Vârsta }\end{array}$ & $\begin{array}{c}\text { Body mass } \\
\text { Masa corporală }\end{array}$ & BMI \\
\hline $\begin{array}{c}\text { Peak pressure } \\
\text { Presiunea maximă }\end{array}$ & $0.248^{* *}$ & $0.248^{* *}$ & $0.208^{* *}$ \\
Pressure-time integral \\
Integrala presiune-timp
\end{tabular}

Correlation coefficient ( $\mathrm{r}$ ): low: 0 - 0.25; weak: 0.26 - 0.50; moderate: $0.51-0.75$; very strong: $0.76-1.00$.

**Significant difference $(P<0.01)$, *Significant difference $(P<0.05)$.

Coeficientul de corelaţie (r): scăzut: 0 - 0,25; slab: 0,26 - 0,50; moderat: 0,51-0,75; foarte puternic: 0,76-1,00.

**Diferenţă semnificativă $(P<0,01)$, * Diferenţă semnificativă $(P<0,05)$.

on the other hand, show an opposite result. A previous research of Hlavacek et al. counted this situation as a reduced toe reflex function as a result of decreased cushioning capability of foot [17]. Furthermore, similar results were found when it comes to the plantar pressure characteristics of the impulses and pressuretime integrals.

In the present study, marked differences of maximum forces and peak pressures were found in the forefoot $\left(1^{\text {st }}-5^{\text {th }}\right.$ metatarsals $)$, midfoot and heel (medial heel and lateral heel) when comparing non-overweight and overweight children to obese children, respectively. This result is in line with studies conducted with children [17, 27] and adults [28]. However, our study also indicates that overweight children only suffer greater overload at the midfoot, followed by the heel, relative to non-overweight children. Overweight and obese children displayed either higher peak pressures or maximum forces in the midfoot, hence increased contact area of the midfoot was not sufficient to compensate for the higher forces generated during walking. Several studies pointed out that long term overload would lead to a lower arch $[15,29]$. Mickle et al. [19] measured the foot anthropometry and arch index of 19 preschool overweight and obese children; their findings confirmed that the flatter foot of overweight and obese children was not caused by the fat pad thickness in the presiunile maxime sunt în mod evident mai mari la copiii obezi, urmați de cei supraponderali în toate regiunile plantare definite, cu excepția metatarsienelor 2-5, care prezintă o tendință opusă. Un studiu anterior efectuat de Hlavacek și colab. a catalogat această situație ca o scădere a funcției de reflex a degetului mare, ca urmare a capacității de amortizare scăzute a labei piciorului [17]. În plus, s-au obținut rezultate similare referitoare la caracteristici ale presiunii plantare precum impulsurile și integralele presiune-timp.

În studiul de față, s-au constatat diferențe semnificative ale forțelor maxime și ale presiunilor maxime în zona antepiciorului (metatarsienele 1-5), în zona centrală și la călcâi (în zonele interioară și exterioară), făcând comparație între copiii cu greutate normală, cei supraponderali și cei obezi. Acest rezultat este în concordanță cu literatura de specialitate referitoare la studiile efectuate cu copii $[17,27]$ și cu adulți [28]. Cu toate acestea, studiul nostru arată în plus că în cazul copiilor supraponderali, se constată o suprasarcină mai mare doar în zona centrală, urmată de zona călcâiului, în comparație cu copiii cu greutate normală. Copiii supraponderali și obezi au prezentat fie presiuni maxime, fie forțe maxime crescute în zona centrală; prin urmare, creșterea suprafeței de contact din zona centrală a piciorului nu a fost suficientă pentru a compensa forțele mai mari generate în timpul mersului. Mai multe studii au subliniat faptul că suprasarcina pe termen lung 
midfoot, but the structural changes in their foot anatomy, not only obesity but also overweight can affect the foot structure of children at preschool age [30]. To our knowledge, it is the first study to investigate the plantar pressure distributions not only for obese children, but also for overweight children when compared to non-overweight children who are from China. We classified all the subjects into groups of non-overweight, overweight and obesity based on the BMI reference norm of Group of China Obesity Task Force as the circumstance may require in China. From our findings, it showed that significant differences for maximum force and peak pressure also existed at the hallux between non-overweight children and obese children. It is a novel finding inconsistent with other studies conducted with obese children $[8,19,27]$. Moreover, in a study conducted by Arnold and his colleagues [31], plantar pressures of thirty healthy adults were measured under different loading conditions $(0,5,10$ and 15 $\mathrm{kg}$ ) respectively, the hallux only displayed significantly higher peak pressures in the $15 \mathrm{~kg}$ loading condition when compared to the control group (0 kg), however, Cousins et al. [27] found no significant difference at the hallux between normal children and obese children. One possible explanation for our finding is that the skeletal structural changes in hallux are not the primary cause of this apparent difference between nonoverweight and obese children. We theorize that this condition may be associated with races and customs which may affect the biomechanical and kinematical function of the foot or alter the walking habits of children. This notion is a speculation and requires further investigation to confirm the result.

Impulse is a variable used to characterize the potential damage caused by the overload to the specific foot structure. The increased impulses at the forefoot of obese children indicate that forefoot endures much more stress. A reasonable explanation attributed this consequence to the lack of capacity to dissipate the forces in this area composed by small bones [18]. Furthermore, our findings show that higher impulses under the midfoot and heel for overweight children relative to non-overweight children. Significantly greater impulses for overweight and obese children in the midfoot and heel imply that there is a probability of ar putea duce la coborârea bolții piciorului [15, 29]. Mickle și colab. [19] au efectuat măsurători antropometrice ale piciorului, studiind bolta plantară la un număr de 19 copii preșcolari supraponderali și obezi, iar concluziile lor au confirmatcă piciorulplatalcopiilorsupraponderali și obezi nu s-a datorat țesutului adipos din zona centrală a piciorului, ci modificărilor structurale ale anatomiei piciorului, dovedind că, nu numai obezitatea, ci și supraponderalitatea poate afecta structura piciorului la copiii preșcolari [30]. Din câte știm, acesta este primul studiu care investighează distribuția presiunii plantare nu numai în cazul copiilor obezi, ci și în cazul copiilor supraponderali, în comparație cu copiii cu greutate normală din China. Toți subiecții au fost clasificați în trei grupe: cu greutate normală, supraponderali și obezi, pe baza indicelui de masă corporală (IMC) de referință stabilit de Grupul pentru Combaterea Obezității din China. Din constatările noastre, a rezultat că au existat diferențe semnificative ale forței maxime și presiunii maxime în zona halucelui între copiii cu greutate normală și copiii obezi. Aceasta este o constatare nouă, care nu se mai regăsește în alte studii efectuate cu copii obezi $[8,19,27]$. Mai mult decât atât, într-un studiu realizat de Arnold și colab. [31], s-au măsurat presiunile plantare la treizeci de adulți sănătoși în diferite condiții de încărcare $(0,5,10$ și $15 \mathrm{~kg})$, iar halucele a prezentat presiuni maxime semnificativ mai mari doar în situația de încărcare cu 15 kg în comparație cu grupul martor $(0 \mathrm{~kg})$; cu toate acestea, Cousins și colab. [27] nu au găsit nicio diferență semnificativă în ceea ce privește halucele în cazul copiilor cu greutate normală și al copiilor obezi. O posibilă explicație pentru constatarea noastră este faptul că modificările structurale ale scheletului la nivelul halucelui nu reprezintă cauza principală a acestei diferențe aparente între copiii cu greutate normală și cei obezi. S-a propus teoria că această situație poate fi asociată cu diferențele de rasă și obiceiuri care pot afecta funcția biomecanică și cinematică a piciorului sau pot modifica obiceiurile de mers ale copiilor. Această noțiune este o speculație și necesită investigații suplimentare pentru a confirma rezultatul.

Impulsul este o variabilă utilizată pentru a caracteriza potențialele leziuni cauzate de suprasolicitarea structurii piciorului. Creșterea impulsurilor în zona antepiciorului la copiii 
developing into deformity in foot structure as a result of excessive mass. Elevated level of the pressure-time integrals in the forefoot and heel of obese children is regarded as a signal of soft tissue damage [6]. Cavanagh and Ulbrecht [32] speculated that increased plantar pressures and foot discomforts of obese children might prevent them from participating in physical activity and hinder their daily locomotion, which in turn can give rise to obesity cycle. All in all, more attention should be given to protect the forefoot and heel of obese children from injury, such as lighter shoes with better cushioning for obese children.

Pressure rate is a relative parameter of dynamic plantar pressure used to describe the rate of pressure changes per millisecond and can assess cushioning function of the foot. Pressure rates were greatest at the heel in all children, but no significant difference was found there. However, Yan et al. indicated a significantly larger pressure rate at the heel for obese children than those for non-obese children [8]. Significantly increased pressure rates were observed under the forefoot and midfoot of obese children. Higher pressure rate caused increased injury risk of foot [33]. Hence, significantly increased pressure rates observed under the forefoot and midfoot of obese children once more confirm the underlying damage to these areas.

Plantar maximum force is associated with contact area, while peak pressure represents the direct force strengths of specific anatomic regions to the ground. Peak pressure and pressure-time integral were thus used to analyze the relationship to age, body mass and BMI. A cross-sectional study of Phethean and Nester [34] drew the conclusion that boys and girls could be pooled to evaluate the plantar pressures. Furthermore, Hennig et al. [35] indicated that there is no significant difference for plantar pressures between girls and boys. Therefore, gender influences were not taken into consideration in this study. Pearson correlation analysis shows a similar result with several studies $[35,36]$ that peak pressure presented a low correlation to age and body mass. Plantar pressures also displayed a very weak positive correlation to BMI, which concurs with a previous study [37], on the other hand, contrasts with another study [11]. We can summarize from our obezi indică faptul că antepiciorul suportă mult mai mult stres. $O$ explicație rezonabilă a atribuit această consecință lipsei capacității de a risipi forțele în această regiune, compusă din oase mici [18]. Mai mult decât atât, descoperirile noastre arată că impulsurile sunt mai mari în zona centrală și în zona călcâiului la copiii supraponderali în comparație cu cei cu greutate normală. Impulsurile semnificativ mai mari în cazul copiilor supraponderali și obezi în zona centrală și în zona călcâiului arată că există o probabilitate de a dezvolta deformări ale structurii piciorului, ca urmare a greutății excesive. Nivelul ridicat al integralelor presiunetimp în zona antepiciorului și în zona călcâiului la copiii obezi este considerat un indicator al leziunilor ușoare ale țesuturilor [6]. Cavanagh și Ulbrecht [32] au speculat că presiunile plantare ridicate și disconfortul la nivelul picioarelor în cazul copiilor obezi ar putea să împiedice participarea acestora la activitatea fizică și să îngreuneze locomoția, ceea ce poate constitui cauza obezității. În concluzie, ar trebui să se acorde mai multă atenție protejării antepiciorului și călcâiului copiilor obezi împotriva leziunilor, de exemplu, prin utilizarea unor pantofi mai ușori, cu o mai bună amortizare.

Evoluția presiunii este un parametru relativ al presiunii plantare în dinamică utilizat pentru a descrie modificarea presiunii pe milisecundă și poate evalua funcția de amortizare a piciorului. Presiunea a fost mai mare în zona călcâiului la toți copiii, dar nu s-a găsit nicio diferență semnificativă. Cu toate acestea, Yan și colab. au indicat o rată a presiunii semnificativ mai mare în zona călcâiului la copiii obezi decât la copii non-obezi [8]. S-a observat o presiune semnificativ mai mare în zona antepiciorului și în zona centrală la copiii obezi. Presiunea mai mare a dus la un risc crescut de accidentare a piciorului [33]. Astfel, presiunea semnificativ mai mare observată în zona antepiciorului și în zona centrală la copiii obezi confirmă încă o dată cauzele leziunilor în aceste zone.

Forța plantară maximă este asociată cu suprafața de contact, în timp ce presiunea maximă reprezintă forța directă a regiunilor anatomice specifice asupra solului. Astfel, s-au utilizat presiunea maximă și integrala presiunetimp pentru a analiza relația acestora cu vârsta, masa corporală și IMC. Un studiu al lui Phethean şi Nester [34] a concluzionat că presiunile plantare se pot evalua la băieți și fete în comun. Mai 
findings that these results shed little light on the variations in plantar pressures for overweight and obese children. Some other factors may be used to explain the increased plantar pressures in them, such as increased contact area [35] and changes in foot skeleton structure [38].

\section{CONCLUSIONS}

This study has demonstrated the plantar pressure distribution of Chinese overweight and obese children during normal walking. Overweight children displayed significantly higher plantar pressures mainly at the midfoot and heel than those of non-overweight children, while obese children endured higher pressures in all regions excepting for $2^{\text {nd }}-5^{\text {th }}$ toes. Excessive and repetitive overload for overweight and obese children can increase the risk of foot damage. Particularly significantly higher pressures at the hallux were found for the first time, which requires further investigation to explore their fundamental cause.

\section{Acknowledgement}

The present study obtained financial support from National Natural Science Foundation of China, grant number: 11502154. The authors would like to acknowledge all the experimenters for subject recruitment and data collection, and to acknowledge all of the study participants who made this study possible. mult decât atât, Hennig și colab. [35] au indicat faptul că nu există nicio diferență semnificativă între fete și băieți în ceea ce privește presiunile plantare. Prin urmare, influența sexului nu a fost luată în considerare în acest studiu. Analiza de corelație Pearson demonstrează un rezultat similar mai multor studii $[35,36]$, și anume că presiunea maximă a prezentat o corelație scăzută cu vârsta și masa corporală. Presiunile plantare au arătat, de asemenea, o corelație pozitivă foarte slabă cu IMC, ceea ce coincide cu un studiu anterior [37], dar, pe de altă parte, se opune unui alt studiu [11]. Din constatările noastre, putem deduce că aceste rezultate nu lămuresc prea bine variațiile presiunilor plantare în cazul copiilor supraponderali și obezi. Se pot lua în calcul alți factori pentru a explica creșterea presiunilor plantare, cum ar fi suprafața de contact mai mare [35] și modificările structurii scheletului piciorului [38].

\section{CONCLUZII}

Acest studiu a demonstrat distribuția presiunii plantare la copiii supraponderali și obezi din China în timpul mersului normal. Copiii supraponderali au prezentat presiuni plantare semnificativ mai mari, în principal, în zona centrală și în zona călcâiului, față de copiii cu greutate normală, în timp ce copiii obezi au suferit presiuni mai mari în toate regiunile $\mathrm{cu}$ excepția degetelor 2-5. Suprasarcina excesivă și repetitivă pentru copiii supraponderali și obezi poate crește riscul de accidentare a piciorului. S-au constatat pentru prima oară presiuni semnificativ mai mari mai ales în zona halucelui, fiind necesare investigații suplimentare pentru a explora cauza fundamentală a acestora.

\section{Mulțumiri}

Prezentul studiu a fost realizat cu sprijin financiar din partea National Natural Science Foundation din China, grant nr. 11502154. Autorii ar dori să mulțumească tuturor experților pentru recrutarea subiecților și colectarea datelor, precum și tuturor participanților care au făcut acest studiu posibil. 


\section{REFERENCES}

1. Aschemeier, B., Lange, K., Kordonouri, O., Danne, T., Pediatric obesity and type 2 diabetes: Strategies for prevention and treatment, Practical Diabetes Int, 2008, 25, 368-375.

2. Dehghan, M., Akhtar-Danesh, N., Merchant, A.T., Childhood obesity, prevalence and prevention, Nutr J, 2005, 4, 24.

3. Chinese Education Newspaper, May 19, 2009; First editor.

4. Petit, M.A., Beck, T.J., Shults, J., Zemel, B.S., Foster, B.J., Leonard, M.B., Proximal femur bone geometry is appropriately adapted to lean mass in overweight children and adolescents, Bone, 2005, 36, 568576.

5. Eliakim, A., Nemet, D., Wolach, B., Quantitative ultrasound measurements of bone strength in obese children and adolescents, J Pediatr Endoerinol Metab, 2001, 14, 159-164.

6. Falk, B., Braid, S., Moore, M., O'Leary, D., Sullivan, P., Klentrou, P., Bone properties in overweight preand early-pubertal boys, Pediatr Exere Sci, 2008, 20, 50-61.

7. Dufek, J.S., Currie, R.L., Gouws, P., Candela, L., Gutierrez, A.P., Mercer, J.A., Putney, L.G., Effects of overweight and obesity on walking characteristics in adolescents, Hum Movement Sci, 2012, 31, 897-906.

8. Yan, S., Zhang, K., Tian, G., Yang, J., Liu, Z., Effects of obesity on dynamic plantar pressure distribution in Chinese prepubescent children during walking, Gait Posture, 2013, 37, 37-42.

9. Adoracion Villarroya, M., Manuel Esquivel, J., Tomas, C., Buenafe, A., Moreno, L., Foot structure in overweight and obese children, Int J Pediatr Obes, 2008, 3, 39-45.

10. Hill, A.P., Parker, A.W., Electromyograph of walking in obese children, Electromyogr Clin Neurophysiol, 1993, 33, 225-233.

11. Burnfield, J.M., Few, C.D., Mohamed, O.S., Perry, J., The influence of walking speed and foot wear on plantar pressures in older adults, Clin Biomech, 2004, 19, 78-84.

12. Zhan, Z., Wu, M., Li, X., Li, H., Foot pressure distribution in 46 university students, Journal of Clinical Rehabilitative Tissue Engineering Research, 2008, 12, 9062-9065.

13. Wang, M., Yu, G., Chen, Y., Yang, Y., Huang, S., Hu, S., Analysis of the plantar pressure distribution of the normal Chinese adult, Orthopedic Journal of China, 2008, 16, 687-690.

14. Cavanagh, P.R., Sims, D.S. Jr., Sanders, L.J., Body mass is a poor predictor of peak plantar pressure in diabetic men, Diabetes Care, 1991, 14, 750-755.

15. Filippin, N.T., Barbosa, V.L.P., Sacco, I.C.N., Lobo da Costa, P.H., Effects of obesity on plantar pressure distribution in children, Braz J Phys Ther, 2007, 11, 495-501.

16. Butterworth, P.A., Urquhart, D.M., Cicuttini, F.M., Menz, H.B., Strauss, B.J., Proietto, J., Dixon, J.B., Jones, G., Landorf, K.B., Wluka, A.E., Fat mass is a predictor of incident foot pain, Obesity 2013, 21, 495-499.

17. Hlavacek, P., Kostelnıkova, L., Comparison of plantar pressures distribution between obese and non-obese children, Clin Biomech, 2008, 23, 662-720. 
18. Dowling, A.M., Steele, J.R., Baur, L.A., Does obesity influence foot structure and plantar pressure patterns in prepubescent children?, Int J Obes Relat Metab Disord, 2001, 25, 6, 845-852.

19. Mickle, K.J., Steele, J.R., Munro, B.J., Does excess mass affect plantar pressure in young children?, Int J of Pediatr Obes, 2006, 1, 183-188.

20. Zonfrillo, M.R., Seiden, J.A., House, E.M., Shapiro, E.D., Dubrow, R., Baker, M.D., Spiro, D.M., The association of overweight and ankle injuries in children, Ambul Pediatr, 2008, 8, 66-69.

21. Group Of China Obesity Task Force, Body mass index reference norm for screening overweight and obesity in Chinese children and adolescents, Chin J Epodemiol, 2004, 25, 2, 97-102.

22. Hallemans, A., Clercq, D.D., Dongen, S.V., Aerts, P., Changes in foot-function paremeters during the first 5 months after the onset of independent walking a longitudinal follow up study, Gait Posture, 2006, 23, 142-148.

23. Menz, H.B., Two feet, or one person? Problems associated with statistical analysis of paired data in foot and ankle medicine, The Foot, 2004, 14, 2-5.

24. Hennig, E.M., Staats, A., Rosenbaum, D., Plantar pressure distribution patterns of young school children in comparison to adult, Foot Ankle, 1994, 15, 35-40.

25. Yan, S., Dong, C., Yang, J., Sun, J., Liu, Z., Effects of gender and BMI on dynamic plantar pressure distribution in children, Journal of Medical Biomechanics, 2010, 25, 363-368.

26. Pett, M.A., Nonparametric statistics in health care research: Statistics for small samples and unusual diatributions, Sage Publications, Thousand Oaks, CA, US, 1997.

27. Cousins, S.D., Morrison, S.C., Drechsler, W.I., Foot loading patterns in normal weight, overweight and obese children aged 7 to 11 years, J Foot Ankle Res, 2013, 6, 36.

28. Hill, A.P., Hennig, E.M., McDonald, M., Bar-Or, O., Plantar pressure differences between obese and non-obese adults: A biomechanical analysis, Int J Obes Relat Metab Disord, 2001, 25, 1674-1679.

29. Dowling, A.M., Steele, J.R., Baur, L.A., What are the effects of obesity in children on plantar pressure distributions?, Int J Obes, 2004, 28, 1514-1519.

30. Mickle, K.J., Steele, J.R., Munro, B.J., The feet of overweight and obese young Children: are they flat or fat?, Obesity, 2006, 14, 1949-1953.

31. Arnold, J.B., Causby, G.R., Pod, G.D., Jones, S., The impact of increasing body mass on peak and mean plantar pressure in asymptomatic adult subjects during walking, Diabet Foot Ankle, 2010, 1.

32. Cavanagh, P.R., Ulbrecht, J.S., Clinical plantar pressure measurements in diabetes: Rational and methodology, Foot, 1994, 4, 123-135.

33. Franklyn-Miller, A., Wilson, C., Bilzon, J., McCrory, P., Foot orthoses in the prevention of injury in initial military training: a randomized controlled trail, Am J Sports Med, 2011, 39, 30-37.

34. Phethean, J., Nester, C., The influence of body weight, body mass index and gender on plantar pressures: Results of a cross-sectional study of healthy children's feet, Gait Posture, 2012, 36, 287290. 
35. Hennig, E.M., Rosenbaum, D., Plantar pressure distribution patterns under the feet of children in comparison with adults, Foot Ankle Int, 1991, 11, 306-311.

36. Veves, A., Fernando, D.J.S., Walewski, P., Boulton, A.J.M., A study of plantar pressures in a diabetic clinic population, Foot, 1991, 1, 89-91.

37. Zhang, S., Zhou, S., Chen, M., Plantar pressure distribution characteristics in male obese adolescents, Journal of Clinical Rehabilitative Tissue Engineering Research, 2011, 13, 6262-6266.

38. Cavanagh, P.R., Rodgers, M.M., liboshi, A., Pressure distribution under symptom-free feet during barefoot standing, Foot Ankle Int, 1987, 7, 262-276.

Article received/Data primirii articolului: 16.06.2016

Accepted/Acceptat la data: 13.09.2016 